\title{
Research on the Evaluation System of Teachers in Universities: Perspectives from China
}

\author{
Qi Yue, Yanyan Cao* \\ Email address: \\ 13356981@qq.com (Yanyan Cao) \\ ${ }^{*}$ Corresponding author
}

School of Economics and Management, South China Normal University, Guangzhou, China

To cite this article:

Qi Yue, Yanyan Cao. Research on the Evaluation System of Teachers in Universities: Perspectives from China. Science Journal of Education. Vol. 5, No. 5, 2017, pp. 196-199. doi: 10.11648/j.sjedu.20170505.12

Received: June 5, 2017; Accepted: June 20, 2017; Published: August 1, 2017

\begin{abstract}
The scientificalization, systematization and standardization of teachers' evaluation system have significant educational value in improving teachers' teaching efficiency, promoting teachers' professional development, and ensuring the quality of education and teaching and promoting the rapid progress of education in our country. On the basis of analyzing a series of problems such as the single evaluation index system, the seriousness of quantification tendency, the lack of evaluation subject status, the evaluation orientation deviation, the lack of feedback mechanism and the lack of objectivity in the evaluation process, this paper puts forward the solutions from the aspects of evaluation purpose, evaluation content, evaluation method, evaluation subject and evaluation feedback.
\end{abstract}

Keywords: College Teacher, Evaluation System, Education Quality, Personnel Training

\section{Introduction}

As the advanced talents and productive production base, the responsibility of cultivating talents, three tasks to enhance productivity, social services, as the base direct producers of university teachers, the qualification, $R \& D$ ability directly affects the cultivation of talents and productive output of high-end degree [1]. People-oriented, the implementation of the strategy of talent strong school, accelerate the construction of high quality to adapt the development of colleges and Universities under the new situation of teachers, colleges and universities in our country face is one of the common problems, enthusiasm and assessment system of university teachers to establish a reasonable and scientific to stimulate college teachers, promote their professional development, and ultimately promote the overall development of colleges and universities.

Despite the rapid development of China's higher education, the evaluation of university teachers will continue to absorb advanced ideas and progress, but China's College Teachers' evaluation at this stage there are still some serious problems: the evaluation index system, quantitative single serious tendency; lack in the evaluation of the subject status of teachers; evaluation of orientation deviation, lack of feedback mechanism; the objectivity of the evaluation process not enough, serious human evaluation [2]. Therefore, in the construction of efficient evaluation system for teachers, should fully reflect the core values of the modern management theory of people-oriented, based on the full analysis of the environment and working characteristics of university teachers, from the evaluation purpose, evaluation content, evaluation method, evaluation subject and evaluation feedback in several aspects of comprehensive consideration, a comprehensive evaluation on University the teacher's teaching, scientific research, ethics and other aspects, to promote the school staff work together to cultivate talent, academic innovation, to provide services for the society, the performance evaluation results into a driving force in fact.

\section{Evaluation Target in Chinese Universities}

The ultimate purpose of university teacher evaluation is to play the role of feedback and motivation, to help teachers 
find their own shortcomings, and better serve the university. At present, our understanding of the value of the university teacher evaluation system is biased, and reasonable university teacher evaluation is not for control, but assessment on the basis of guidance and promotion [3].

The evaluation of university teachers is an important means and way of teacher professional development. While paying attention to the results of performance evaluation, more attention should be paid to the feedback of performance evaluation results. Directly linked by the performance evaluation results and teachers' income, employment, promotion, rewards and punishment, can give full play to the performance evaluation of the situation, the formation of benign competition for going up and down, further improve the enthusiasm and enthusiasm of teachers, to promote teachers' development [4]. At the same time, the evaluation of university teachers should play the function of development, with the perspective of development, ongoing evaluation of teachers, through the evaluation to promote teachers' Reflection on their own work, make the teacher found himself in teaching and scientific research and other work of the advantages and disadvantages of education combined with practical activities to their continuous development and self perfection.

\section{Improve the Evaluation Content in Chinese Universities}

The evaluation of university teachers tend to focus only on the teachers' education level, professional level, scientific research ability, scientific research level and ignore the complexity of teachers' work, ignoring the moral and political theory level, physical and mental health quality [5]. Re dominant, light and recessive, heavy results, light process, to a certain extent exposed the utilitarian, the content of the teacher evaluation of multi-dimensional and development has not been paid attention to, it is difficult to achieve a comprehensive, objective and impartial evaluation of teachers. At the same time, the common and universal too much emphasis on the evaluation, with the same set of indicators to measure all the teachers, schools and teachers neglect the characteristics of group differences, negative impact inevitably to the personal development of teachers, each teacher can not effectively play the advantages and strengths, and will hurt their work enthusiasm.

Teachers in Colleges and universities is a kind of mental labor, working with complex object, many factors in the process of teaching is not easy to determine, the education period is long, the effect of education lag, the collective characteristics of educational achievement. At the same time, the work of university teachers is a complicated labor, even in the same school, there are also differences between subjects, professional teachers' workload, using the same evaluation index to evaluate all the teachers, but also can not effectively play the advantages and strengths of each teacher.

Colleges and universities should be based on the goal of their respective schools, with the school for a period of time, the focus of development and target management system, set up their own strategy of reform and development of teacher performance evaluation system, and according to the characteristics of different disciplines, departments and their own conditions set out specific weights of evaluation content [6]. The 360 degree evaluation model and the scientific analytic hierarchy process are adopted to carry out the classified evaluation and classification instruction for teachers, and encourage teachers to engage in basic theory and innovative research, and to objectively determine the content and weight. Increase the evaluation on the ability of teaching practice, research and innovation ability, service consciousness, moral and other aspects, encourage teachers to concentrate on improving teaching quality and cultivating outstanding students, the evaluation index system reflects the requirements of both ability and political integrity.

\section{Change the Evaluation Methods in Chinese Universities}

In the social and academic background of large data analysis, the performance evaluation of teachers also needs to be integrated with new technologies and methods to achieve the goal of keeping pace with the times. The traditional method of evaluation of university teachers mainly from the three aspects of teaching, scientific research, scientific research achievement award by the school unified production form scoring according to the project, and the results of the three aspects constitute one teacher one year evaluation results [7]. This kind of evaluation has strong subjective consciousness judgment, and it does not carry on the thorough excavation to the implicit information, it is difficult to reflect the teacher's comprehensive situation comprehensively and accurately.

The era of big data through the technical aspects of the combination of big data evaluation methods, promote the teacher evaluation from the concept, contents and methods of profound changes, which make the evaluation has been out only to evaluate the results of the circle, through technical means to fully and accurately record the teacher in the teaching and scientific research in the process of behavior, attitude and practice, making the evaluation more the scientific, systematic and comprehensive. At the same time, the differences in the personality and respect teachers' evaluation, through the introduction of third party organizations to promote the diversification of the evaluation subject and construction process of teacher evaluation system based on cloud computing, big data, data visualization technology, promote the evaluation methods from experience to digitalization. But these technologies are not known, once widely, will greatly enhance the reliability and validity of teacher evaluation system, reduce the tension and conflict in the process of evaluation, teachers play a leading role should be the function of evaluation system. 


\section{Pay more Attention to the Evaluation Subjects in Chinese Universities}

Scientific and effective teacher performance evaluation should be based on teachers, because teachers are the main body whether they are from the main body of the school or the dominant force of the realization of the school's strategic objectives. In the evaluation process, the lack of teacher's main body status not only affects the validity of evaluation, but also can not arouse the initiative and initiative of teachers [8]. In order to further promote the development of teachers, deepen the teaching reform, the teaching level of teacher education to achieve the purpose of continuous improvement, more attention should be paid to the importance of teachers' self-evaluation in the teacher evaluation system, the school should give teachers autonomy, allowing teachers to participate in the evaluation process. In the evaluation, teachers are no longer passive evaluation objects, but and other evaluation, can take the initiative to describe their work and status, expounds his views, not only can self praise, can also carry out self-criticism. In this way, the teacher as the master of his own evaluation, there is no need to meet or prevent others in the passive evaluation, so that the process of self-evaluation can become a process of self reflection and development [9]. At the same time, colleges and universities in China should allow teachers to participate in the formulation of teaching evaluation forms, or allow teachers to raise questions they want to know from students. At the end of the evaluation, the teacher will discuss the results of the evaluation and listen to the opinions of the teachers to promote the improvement of teaching and the development of teachers' profession.

\section{Establish the Evaluation Feedback Mechanism in Chinese Universities}

In view of the complexity of teacher evaluation work, it is carried out that the teacher evaluation, to effectively protect the legitimate rights and interests by evaluating the teacher, when judged teachers on the evaluation results do not agree or not satisfied, can be through a channel or to express their own opinions, so as to enhance the teachers' evaluation system of identity, increase the fair and reasonable and improve the teacher evaluation system. In some of our colleges and universities, teachers' complaint and Reconsideration on the evaluation results of the channels and procedures are not open and transparent, lack of supervision, when teachers had lower scores in the evaluation of professional titles or the annual performance evaluation, do not know where to appeal [10]. Many teachers have been treated unfairly, just take a bear is calm, take a step as boundless as the sea and sky 'attitude and destroyed teeth pharynx to the stomach, finally to do one day at a time attitude, teaching enthusiasm dampened and blow, the performance is always in the state of mediocrity [11]. Thus, the establishment of teacher grievance procedure is scientific and reasonable, standardized, reasonable demands can make teachers expressed [12], can effectively form the school culture atmosphere of trust, cooperation, can also play the teachers and management institutions promote mutual supervision function in Colleges and universities.

\section{Conclusion}

The basic purpose of teaching quality evaluation is to fully mobilize the enthusiasm of teachers' teaching work through evaluation, and constantly promote the development of teachers. Construction of College Teachers' evaluation system of scientific, systematic and standardized, to improve teachers' teaching efficiency, promote teachers' professional development, and ensure the quality of education and teaching, promote the education of our country faster progress has significant meaning and value of science education. Based on the analysis of the rapid development of China's higher education trend, points out the importance of constructing teacher evaluation system in Colleges and universities, and analyzes a series of problems in the current evaluation of university teachers in our country are based on the connotation of the evaluation of teachers in Colleges and universities. In view of the above problems, this paper puts forward the following suggestions from five aspects: the purpose of evaluation, the content of evaluation, the method of evaluation, the subject of evaluation and the feedback of evaluation.

\section{Acknowledgements}

The research is supported by National Humanities and Social Science in China under Grant 17BJR01063, Guangdong Natural Science Foundation under Grant 2014A030313442, Guangzhou Philosophy and Social Science under Grant 2017GZYB43 and Guangdong Education Ministry of Higher Education Teaching Reform Project named Study and Practice of the Training Mode of Innovative Talent based on the Internet Background.

\section{References}

[1] Liu Z, Wang H, Zhang H. Construction of an evaluation system for promoting the development of teachers [J]. Tsinghua University Education Research, 2015, 36 (6): 81-85.

[2] Li L, Zhang M. The development of university teachers' performance evaluation process [J]. Economic Research Guide, 2016, 3 (29): 58-59.

[3] Cao R. Teachers' evaluation system problems and improvement [J]. Journal Of National Academy Of Education Administration, 2012, 18 (3): 73.

[4] $\mathrm{Xu} \mathrm{S}$. Influence factors and construction principles of university teacher evaluation system [J]. Faculty Research of Chinese Universities and Colleges, 2008, 16 (4): 17-20.

[5] Wang K. Performance evaluation system of american college teachers and its enlightenment to china $[\mathrm{J}]$. Journal of Northeastern University, 2013, 15 (6): 642-646. 
[6] Li C. Problems and countermeasures in academic evaluation of college teachers [J]. Modern Educational Science, 2006, 17 (11): $81-84$

[7] Xu C, Jiang Z, Zhou J. Problems And Improvement Strategies of Performance Evaluation of University Teachers [J]. Journal of Heilongjiang Institute of Education, 2017, 36 (1): 20-22.

[8] Wang K, Ho J. Strategic orientation from the perspective of performance evaluation of university teachers innovative research [J]. Journal of Liaoning University: Philosophy And Social Science Edition, 2012, 40 (6): 99-103.

[9] Yin M. Reflections on the feedback of teaching effectiveness evaluation of university teachers [J]. Journal of Graduate School of Chinese Academy of Social Sciences, 2010, 23 (4): 141-144.
[10] Zhu S. On university teachers' performance evaluation implementation suggestion [J]. Modern Economic Information, 2016, 26 (13): 77.

[11] Wang S. Review of research and practice on teaching evaluation of university teachers in china in recent ten years [J]. Jiangsu Higher Education, 2008, 18 (3): 70-73.

[12] Chen Z. Analysis of some changes in teacher evaluation [J]. Teacher Education Research, 2012, 24 (5): 62-66. 